\title{
Acessibilidade para estudantes cegos e baixa visão: análise dos objetos educacionais digitais de física
}

\author{
Ivani Cristina Voos* \\ Gabriela Kaiana Fereira**
}

\section{Resumo}

Este artigo tem como objetivo realizar uma breve análise dos Objetos Educacionais Digitais (OED) disponíveis nas coleções didáticas da componente curricular Física selecionadas no Programa Nacional do Livro Didático (PNLD/2015), a fim de averiguar se os mesmos apresentam recursos de acessibilidade para estudantes com deficiência visual. Foram analisadas as quatro coleçôes de Física que disponibilizaram o recurso digital como parte integrante da obra. Discutir a acessibilidade disponibilizada nos recursos digitais se faz necessária visto o crescente número de estudantes com deficiência visual no ensino regular. Após as análises concluiu-se preliminarmente que nenhuma das quatro coleçốes apresenta acessibilidade para os recursos, fato esse que pode ser negativo para o processo educativo de estudantes cegos e baixa visão que faráo uso dos OED.

Palavras-chave: Estudantes cegos e baixa visão; Objeto Educacional Digital (OED); Física; Acessibilidade.

\footnotetext{
* Professora do Instituto Federal de Santa Catarina, Araranguá, Santa Catarina, Brasil.
}

** Professora da Universidade Federal do Paraná, Curitiba, Paraná, Brasil. 


\section{Acessibility for blind and low vision students: analysis of physics' digital educational objects}

\section{Abstract}

The purpose of this article is to conduct a brief analysis of Digital Educational Objects (OED) available in Physics textbooks selected for the National Textbook Program (PNLD/2015) in order to verify whether they have accessibility features for visually impaired students at basic education. Four collections that provide digital resource as part of the work, according to the Guide Textbook, were analyzed. Discuss the accessibility available in digital resources is necessary because of the increasing number of students with visual impairments registered in regular schools. After the analysis, we can conclude, preliminarily, that none of the four collections has accessibility to the media resources that can help eliminate possible methodological barriers, a fact that can be negative to the education of blind students and low vision that will make use of OED.

Keywords: Blind students and low vision; Digital Educational Objects (OED); Physics.

\section{Introdução}

Atualmente o número de matrículas de alunos com deficiência tem crescido muito no ensino regular, em especial na educação básica. Apesar de não discriminar os estudantes por tipo de deficiência, o Censo da Educação Básica (BRASIL, 2014) aponta que 648.921 estudantes com deficiência estáo matriculados na educação básica, sendo que entre os anos de 2012 e 2013 houve um crescimento de 4,5\% nas matrículas desses estudantes. Este crescimento aponta para a necessidade cada vez maior das escolas se adaptarem às necessidades desses estudantes, a fim de ofertar uma educação de qualidade e em condições de igualdade para todos (TORRES e MAZZONI, 2004). Pensando nisso entendemos o quão importante torna-se refletir acerca dos materiais didáticos que vem sendo utilizados para possibilitar os processos de ensino-aprendizagem de estudantes brasileiros. Entre os materiais didáticos presentes em sala de aula, o livro didático parece ser o mais frequentemente utilizado, tendo em vista também a execuçáo de programas desenvolvidos pelo Ministério da Educação (MEC), como o caso do Programa Nacional do Livro Didático (PNLD) que atualmente avalia, indica, compra e distribui coleçóes didáticas para todos os anos escolares da educação básica pública do país. $\mathrm{Na}$ edição de 2015, as coleçôes para o ensino médio apresentam inovaçôes com relação às formas de apresentação, compostos por livros digitais e livros impressos, além de ferramentas e recursos digitais. Fato este que torna importante analisar os livros didáticos que são utilizados nas escolas básicas e, a partir de 2015, também, os objetos digitais educacionais que os acompanham.

Nesse contexto, buscamos realizar uma breve análise dos Objetos Educacionais Digitais (OED) que acompanham os livros didáticos da componente curricular 
Física selecionados no PNLD/2015 com o objetivo de averiguar se os mesmos apresentam recursos de acessibilidade para estudantes com deficiência visual matriculados na educação básica.

Diante dos dados do Censo Escolar (2014) e da presença de alunos com DV na educação básica, muitos questionamentos foram surgindo, entre os quais elencamos alguns que nortearão esse estudo: é possível que alunos com cegueira e baixa visão matriculados no Ensino Médio das escolas utilizem os OED dos livros didáticos de Física do PNLD/2015 em condiçóes de igualdade com os demais estudantes da turma? Os OED disponibilizados nas quatro coleçôes da Física estão acessíveis para estudantes cegos ou com baixa visão? Os professores de Física na escola são capazes de realizar as adaptaçóes, caso sejam necessárias?

Tais questionamentos justificam este estudo e fomentam uma importante discussão tanto sobre os critérios utilizados para avaliação e indicação dos recursos digitais, quanto sobre as questôes de produçẫo destes materiais, que deveriam seguir normas de acessibilidade conforme indicam os autores Torres e Mazzoni (2004), Grécio (2011) e Nunes et. al. (2011).

Segundo o Guia do livro didático, as coleçôes disponibilizadas passaram por um criterioso processo de avaliação por especialistas das áreas específicas de ensino (BRASIL, 2014, p. 8 - 9). Porém, a questão que fica é: por que tais materiais não são avaliados em parceria com profissionais da área da Educação Especial? O trabalho colaborativo entre profissionais das diferentes áreas de ensino - Educação Especial e Física - pode ser uma alternativa interessante para enfrentar a problemática dos processos educativos de alunos cegos e baixa visão em componentes curriculares de Ciências da Natureza, conforme indicam os estudos de Mendes, Vilaronga e Zerbato (2014), Cabral et. al. (2014) e Voos et. al. (2016).

Outro aspecto relevante a ser evidenciado é o fato de que tais componentes curriculares são ainda fortemente baseadas na visualidade, o que pode trazer impedimentos para a participação do estudante com DV, podendo ser enfrentada pela colaboração entre docentes. Sobre o aspecto da visualidade em aulas de Ciências da Natureza (CN) Soler (1998) explica que:

Atualmente as matérias de ciências são ensinadas em diferentes níveis acadêmicos apenas a partir do parâmetro visual. Isto é porque nós nos esforçamos para homogeneizar nossos alunos em uma única capacidade a qual consideramos predominantemente: o sentido da visão (SOLER, 1999, p.1, tradução das autoras).

$\mathrm{O}$ autor apresenta a visualidade como algo limite no ensino de $\mathrm{CN}$ para estudantes cegos e baixa visão. Percebe-se que elementos visuais estão bastantes presentes nos OED dos livros didáticos que propomos analisar nesse trabalho, o que provavelmente pode se tornar uma barreira no processo educativo desses estudantes. A visualidade foi tema de discussão recorrente na História da Ciência, eventos como observar, analisar e descrever fenômenos, utilizar instrumentos ópticos como telescópio ou microscópio, sempre foram muito relevantes e para os quais o sentido da visão era imprescindível. Aristóteles defendia que "[...] a vista é, de todos os nossos 
sentidos, aquele que nos faz adquirir mais conhecimentos [...]” (Chauí, 1988, p. 47). Esta é apenas uma das inúmeras passagens históricas e filosóficas acerca da soberania do olhar (Novaes, 1988). Tais representaçôes podem ainda exercer forte influência na maneira como as $\mathrm{CN}$ são lecionadas nas escolas, como os materiais didáticos destas componentes curriculares são preparados e como se dá a formação inicial de professores da área. Parece que os OED tomaram este mesmo caminho: a visualidade como elemento central. É importante destacar que não há problemas em utilizar vídeos, infográficos, representaçóes visuais e outros recursos digitais pautados no visual, a inadequação está na forma como são disponibilizados para estudantes cegos e com baixa visão. Atualmente, são inúmeros os recursos de Tecnologia Assistiva existentes e disponibilizados gratuitamente na rede mundial de computadores que podem ser acessados e utilizados por professores e desenvolvedores dos materiais digitais, assim como normas e diretrizes nacionais e internacionais que devem ser seguidas por desenvolvedores (GRÉCIO, 2011). Tornar acessível os recursos digitais e "instrumentalizar" o professor para que enfrente tal problemática deveriam ser parte das açóes governamentais, em especial, à disponibilidade dos OED já no formato acessível.

Pensando nestas questôes, discutiremos o que são os $\mathrm{OED}$, e partindo da breve análise realizada procuraremos apontar possíveis limites para os processos educativos de estudantes cegos e baixa visão participantes de aulas de Física no Ensino Médio. No final, propomos um pequeno roteiro com dicas buscando apontar possíveis contribuiçốes para um trabalho pedagógico acessível com o uso dos OED.

É preciso que os professores reflitam que mesmo o que é visível por meio de imagens ao aluno vidente, em uma visão não ingênua sobre o processo de construção do conhecimento, náo se trata de uma imagem tal qual a realidade, mas de uma representação conceitual, de um modelo não definitivo, e que qualquer modelo físico tem suas limitações, suas validades de aplicação, como as representaçôes contidas nos livros didáticos envolvendo conteúdos como a física de partículas, ondas sonoras, óptica, eletromagnetismo (GIL PEREZ et. al., 2001).

\section{O Programa Nacional do Livro Didático: uma análise dos OED da componente curricular física}

O Programa Nacional do Livro Didático (PNLD), realizado pelo MEC, tem como objetivo subsidiar o trabalho pedagógico dos professores por meio da distribuição de coleçôes de livros didáticos aos alunos da educação básica. Para cumprir com esse objetivo, trienalmente as obras são submetidas à avaliação do MEC que publica o Guia de Livros Didáticos com resenhas das coleçóes consideradas adequadas e aprovadas. Esse guia é encaminhado às escolas que selecionam, entre os títulos disponíveis, aqueles que melhor atendem ao seu Projeto Político Pedagógico (BRASIL, 2014).

Pela terceira vez, em 2015, o programa atendeu a componente curricular Física no Ensino Médio, com um crescente número de obras aprovadas, o que reflete uma maior sintonia e aproximação entre o processo de elaboraçáo das coleçôes e as exigências dos editais de convocação para a inscrição e avaliação das obras didáticas pelo PNLD, proporcionando, consequentemente, um maior número de opçóes para 
os professores. Na atual edição do PNLD/2015, surgem, pela primeira vez obras multimídias compostas por livros digitais, contendo OED, além dos tradicionais livros impressos, inovação importante que parece sinalizar para a incorporação das novas tecnologias no enriquecimento dos processos educativos.

A avaliação das obras didáticas passa por um rigoroso processo às cegas por docentes e pesquisadores, especialistas da área de Física e de Ensino de Física. Cada obra passa pela análise individual de dois avaliadores, que depois são discutidas de modo a se estabelecer um consenso sobre as análises e do resultado final. Por fim, juntamente às coordenações de área e representação da comissão técnica são emitidos pareceres e resenhas das obras recomendadas com a finalidade de orientar o trabalho do professor na escolha da coleção didática a ser adotada na escola. Todo o material produzido é publicado pelo MEC no Guia de Livros Didáticos: PNLD 2015 - Física - Ensino Médio (BRASIL, 2014), incluindo os critérios de avaliação, os conteúdos das fichas de avaliação pedagógica e as resenhas dos 14 livros aprovados para a componente curricular Física. Tendo em vista a presença de conteúdo digital em algumas obras, a ediçẫo do PNLD/2015 apresenta também critérios de avaliação específicos para o conteúdo digital. Da totalidade das coleçôes didáticas, apenas quatro possuem conteúdo digital e são classificadas como Coleção do Tipo 1 . As demais, que não apresentam conteúdo digital, são classificadas como Coleção do Tipo 2.

Os critérios de avaliação do conteúdo digital foram reunidos em cinco blocos: 1) Legislação e cidadania, 2) Abordagem metodológica e proposta didático-pedagógica, 3) Conceitos, linguagens e procedimentos, 4) Orientaçôes didáticas aos objetos educacionais digitais, 5) Projeto editorial, organização e apresentação do conteúdo digital.

No entanto, em nenhum momento são mencionados critérios de acessibilidade aos recursos para estudantes cegos ou com baixa visão, apesar de haver uma preocupação no que se refere à legibilidade gráfica aos videntes no último bloco, como segue:

A legibilidade gráfica é adequada (tamanho e espaçamento das le-
tras, palavras e linhas; formato, dimensōes e disposiçáo dos textos
na página, uso de cores) tanto no âmbito específico de cada OED
quanto nas demais páginas referentes ao conteúdo digital (BRA-
SIL, 2014, p. 32)

Antes de analisar propriamente os OED presentes nas obras didáticas, é importante conceituar o que são estes recursos. De acordo com Graciando e Fireman (2010), OED são entendidos:

[...] como sendo recursos digitais que podem ser baseados em textos, páginas em HTML, gráficos, ilustrações, animaçóes, simulaçóes, imagens e outros, que sejam modulares e reutilizáveis e que estão voltados para a questão da aprendizagem nos mais variados níveis e modalidades de ensino, cuja finalidade seja a sua utilização como ferramenta, um recurso, um instrumento para o ensino, de forma intencional, ou seja, um ODA é um material digital utilizado e criado especificamente para que seus usuários 
apropriem-se de algum tipo de conhecimento (GRACINDO e FIREMAN, 2010, p. 77).

Como se pode perceber pela definição adotada pelos autores, são recursos pautados, quase que exclusivamente, no sentido da visão. Sendo assim, se a acessibilidade náo for um critério levado em consideração desde a concepção/organização, estudantes cegos e com baixa visão poderão ter barreiras educacionais de acesso ao conteúdo proposto por esse recurso. Podemos antecipar que os OED aqui analisados demonstram não terem seguido quaisquer critérios e normas de acessibilidade, e assim sendo se faz necessária a adaptação posterior desse material pelo professor para o uso em sala de aula, a fim de que esses estudantes possam usufruir dos recursos em condições de igualdade com os demais. Porém, a questão ainda latente é: esses professores estariam capacitados a fazer tais adaptaçôes? Não seria esta uma questão a ser levada em consideração desde a gênese do processo de concepção da obra didática? O próprio edital de convocaçáo para o processo de inscriçáo e avaliação de obras didáticas para o programa reconhece que os $\mathrm{OED}$ são recursos visuais explicitados no Item 4.2.3 como:

Entende-se por objetos educacionais vídeos, imagens, áudios, textos, gráficos, tabelas, tutoriais, aplicaçôes, mapas, jogos educacionais, animaçóes, infográficos, páginas web e outros elementos (BRASIL, 2013, p.3).

Em uma breve análise realizada nas coleçôes didáticas do Tipo 1, conforme apresentamos na Tabela 1, percebe-se que o conteúdo digital das obras didáticas consiste basicamente em vídeos, infográficos e ilustraçôes. Também que as coleçôes 'Compreendendo a Física', 'Física' e 'Física - Contexto e Aplicações', obras numeradas como 1, 2 e 3 na Tabela 1, pertencem ao mesmo grupo editorial e os OED têm muitas semelhanças entre si, inclusive no que concerne às questóes de acessibilidade. Já a coleção 'Quanta Física' apresenta diferenças, entre elas a quantidade de recursos digitais disponibilizados, conforme tabela 1 . Nesta coleção, percebe-se um investimento em acessibilidade, como uma barra com recursos para pessoas com baixa visão. Entretanto, possivelmente, tal recurso não seja suficiente para que o estudante baixa visão e cego conquistem sua autonomia para o uso. A pesquisa de Grécio (2011) apresentou uma avaliação realizada por estudantes cegos acerca de OEs. A mesma indicou que entre os OEs de Física analisados os estudantes apontaram recursos de acessibilidade que facilitavam a navegaçáo de forma autônoma, porém em diferentes momentos foi necessária a mediação da pesquisadora para que o uso do OEs pudesse ser realizado. A conclusão apresentada é que os OEs ainda carecem de recursos acessibilidade, análogo ao que apresenta a coleção "Quanta Física".

As definiçóes apresentadas correspondem com os tipos de recursos disponibilizados e utilizados pelos autores das obras didáticas apresentadas na Tabela 1, tais como: infográficos, simuladores, ilustrações, vídeos. Todos estes recursos digitais são muito relevantes no processo de aprendizagem de componentes curriculares das $\mathrm{Ci}$ ências da Natureza, porém para estudantes com tais características os mesmos podem se constituir como barreiras pedagógicas, metodológicas ${ }^{1}$, de comunicação e informação ${ }^{2}$. Barreiras essas que pela definição adotada, não podem ser enfrentadas de forma isolada pelo professor da Física. 
Tabela 1: Apresentando as 4 coleçôes e seus OED.

\begin{tabular}{|c|c|}
\hline Quais as Coleçóes com OED? & $\begin{array}{l}\text { Que tipo de Objetos Educacionais Digitais } \\
\text { apresentam? }\end{array}$ \\
\hline 1) Compreendendo a Física & $\begin{array}{l}35 \text { OED em } 3 \text { Volumes: } \\
19 \text { vídeos, } 9 \text { infográficos, } 1 \text { animaçáo, } 5 \text { simuladores, } 1 \\
\text { jogo. }\end{array}$ \\
\hline 2) Física & $\begin{array}{l}28 \text { OED em } 3 \text { Volumes: } \\
18 \text { vídeos, } 3 \text { infográficos, } 1 \text { animaçáo, } 5 \text { simuladores, } 1 \\
\text { jogo. }\end{array}$ \\
\hline 3) Física - Contexto \& Aplicaçóes & $\begin{array}{l}44 \text { OED em } 3 \text { Volumes: } \\
27 \text { vídeos, } 15 \text { infográficos, } 10 \text { simuladores, } 2 \text { animaçóes, } \\
2 \text { jogos. }\end{array}$ \\
\hline 4) Quanta Física & $\begin{array}{l}24 \text { OED em } 3 \text { Volumes: } \\
13 \text { infográficos, } 1 \text { simulador, } 10 \text { animaçốes. }\end{array}$ \\
\hline
\end{tabular}

A partir de agora faremos uma breve descrição dos OED por coleção didática (apresentadas na Tabela 1) e apresentação da análise sobre acessibilidade realizada nos materiais disponibilizados pelas editoras nos sites. Tendo em vista a dificuldade em estabelecer contato com as editoras que não responderam aos contatos quanto à disponibilização dos OED no formato em que as escolas tiveram acesso, e que possivelmente haja diferenças entre os materiais disponibilizados na web e os disponibilizados para as escolas. De qualquer forma, entende-se que os recursos de acessibilidade devem estar também nos OED disponíveis na web, a fim de que fossem analisadas e conhecidas pelos professores da área e os estudantes, como recomendado pelas normas e diretrizes nacionais e internacionais (GRÉCIO, 2011).

As três coleçóes 'Física', 'Compreendendo a Física' e 'Física - Contexto e Aplicação' apresentam muitas semelhanças na forma de apresentação dos OED, e, consequentemente, na inexistência de recursos de acessibilidade. A partir da análise realizada, foi possível elencar alguns aspectos, por exemplo, o fato de todos os recursos serem exclusivamente visuais, o que exige do estudante o sentido da visão para acessar as informaçôes e conteúdos. O OED disponibilizado no site da editora não faz nenhuma referência à acessibilidade, como: alteração de cor e tamanho de fonte, lupa, e principalmente áudio-descrição, nem mesmo no layout inicial para encontrar o conteúdo. Pode-se perceber ainda que as informações de acesso e navegação estão dispostas unicamente escritas, não tendo as mesmas informaçóes em áudio, o que impede que o estudante com cegueira ou baixa visão consiga se localizar e buscar as informações necessárias, pois os leitores de tela não fazem a leitura das imagens (quadro no qual se encontra a instrução escrita). Os vídeos não possuem áudio-descrição, apenas legenda escrita, que embora estejam em Língua Portuguesa, não estão áudiodescritas. Fato este exigirá do professor de Física, quando usar este material em sala de aula, crie adaptaçóes para o uso de estudantes cegos e baixa visão.

A última coleção analisada é a "Quanta Física" que disponibiliza 24 OED (13 infográficos, 1 simulador, 10 animações). O OED dessa coleção não está disponível na íntegra no site da editora, foram feitos contatos com a mesma que náo o dispo- 
nibilizou alegando que não foram distribuídos às escolas no período de realização da pesquisa.

Diante dos dados elencados, reconhecem-se alguns limites nas análises, em especial, o fato de não terem sido realizadas em parceria com estudantes cegos e baixa visão e por terem sido realizadas sobre os materiais disponibilizados nos sites das editoras $^{3}$, o que pode apresentar diferenças com os materiais que foram distribuídos às escolas do país. Recursos digitais têm muita relevância educacional para os estudantes e professores, o fato de os mesmos não estarem acessíveis para estudantes cegos e com baixa visão os tornam incompletos, pois podem contribuir para exclusão destes estudantes em aulas de Física. Embora o edital de convocação para o processo de inscrição e avaliação de obras didáticas para o PNLD/2015 faça menção à acessibilidade obrigatória para o livro do estudante e do professor a ser oferecido em formato MecDaisy ${ }^{4}$, não faz referência à acessibilidade no OED disponibilizados nas obras de Tipo 1, o que apontamos como limite no edital.

\section{Contribuições para a acessibilidade nos Objetos Educacionais Digitais}

Como já discutido, pensar em recursos de acessibilidade nos materiais didáticos utilizados em salas de aula com estudantes cegos e baixa visão é algo indispensável. Torres e Mazzoni (2004) explicam que:

A não-observância dos princípios do design for all no espaço digital, pelos autores dos materiais disponibilizados nessa forma, pode ser considerada como uma discriminação feita a milhares de usuários (TORRES e MAZZONI, 2004, p. 152).

Pensando em possíveis contribuições para o enfrentamento das barreiras educacionais que podem ser oriundas das abordagens metodológicas, linguagens e procedimentos empregados nos OEDs, apresentamos na sequência um roteiro que visa indicar possibilidades para que os professores possam pensar a participação dos estudantes com DV. Este roteiro não deve ser considerado algo fechado, mas como contribuiçóes para que o professor da componente curricular consiga fazer uso dos OEDs e os estudantes cegos e baixa visão possam participar em condiçôes de igualdade.

Para esta parte foram selecionadas duas obras para análise e destas destacamos o conteúdo referente à Física de Partículas, são eles: o volume 3 da coleção Compreendendo a Física e o volume 3 da coleçáo Física. A partir dessa análise foi elaborado um roteiro das adaptaçóes e recursos de acessibilidade que podem ser oferecidas ao estudante ${ }^{5}$. Porém, é importante lembrar que pessoas com cegueira e baixa visão não são iguais por terem a mesma deficiência, bem como, não se adaptam e aceitam recursos de Tecnologia Assistiva de forma isonômica. Portanto, faz-se primordial que o professor da sala de aula converse com o estudante a fim de coletar o maior número de informaçôes acerca das experiências sensoriais já adquiridas, e conhecer os limites e as potencialidades dos recursos, tendo condiçôes de apontar os caminhos a serem traçados. De acordo com Laplane e Batista (2008), 
[...] o que determina o tipo de recurso a ser adotado é a necessidade, interesse, disposição e objetivos do próprio sujeito, assim como as condiçóes de inserção sociocultural e familiar que tornarão um recurso mais adequado ou viável que outro. Não há, portanto, uma conduta única que possa ser seguida em todos os casos, mas sim, estratégias de caráter geral que podem facilitar o trabalho escolar e derrubar barreiras de comunicaçáo e acesso ao conhecimento. Para começar é necessário prestar atenção ao uso que o aluno faz dos canais sensoriais que possui, sejam eles visuais, táteis ou auditivos, às suas características pessoais e à sua história de desenvolvimento e aprendizagem (LAPLANE e BATISTA, 2008, p. 216).

As autoras corroboram com o entendimento que aqui procuramos explicitar: somente a pessoa que vive a deficiência tem experiência suficiente para melhor apontar os limites e as potencialidades dos recursos de acessibilidade e as diferentes formas de apresentação do material didático, o que não significa que fará escolhas acerca dos conteúdos e metodologias usadas pelo professor. Como explicam Torres, Mazzoni e Mello (2007) "nem toda pessoa cega lê em Braille, nem toda pessoa surda se comunica em língua de sinais" (p. 1).

O roteiro de acessibilidade foi elaborado, como descrito acima, com base em um conteúdo: a Física de Partículas, cujo OED é intitulado como "LHC - o grande colisor de Hádrons".

As duas coleçôes digitais oferecem orientaçôes didáticas destinadas ao professor sobre a utilização do OED, porém as mesmas não abordam a questão da acessibilidade. Como objetivo do OED e do conteúdo denominado Física de Partículas, mais especificamente no que diz respeito aos aceleradores de partículas, os autores destacam a importância dos alunos conhecerem a estrutura e funcionamento do LHC (Large Hadron Collider), bem como enfatizam o papel da Física no desenvolvimento da estrutura denominada LHC. Nas orientaçôes didáticas os autores da obra elencam, ainda, a importância de expor aos alunos que o CERN (Conseil Européen pour la Reaserche Nucléaire) foi responsável por construir o LHC e desenvolver a World Wide Web, motivado pela necessidade de se estabelecer uma comunicação eficiente entre os departamentos do CERN, fato este que significou muito para a evolução das relações de interação, comunicação e desenvolvimento da sociedade.

Portanto, não se percebe nas orientaçóes qualquer tópico que sinalize ao professor a importância de áudio-descrever as imagens do livro, nem mesmo de explicar com recursos táteis a representação visual das partículas, já que as mesmas são invisíveis para todas as pessoas. A pesquisa de Kolitsky (2014) indica a impressão em 3D das imagens e recursos visuais disponibilizados nos OEs para que os estudantes com DV possam fazer uso dos mesmos sem limitaçóes.

Quanto à utilização do OED a orientação dada ao profesor, é que reserve um tempo para utilizá-lo na sala de aula após ter realizado o estudo do conteúdo.

Diante isso, o que pode fazer o professor para que o estudante, cego e baixa visão, participe em condiçôes de igualdade na aula que faz uso do OED? Sugerimos alguns aspectos que podem ser observados para que a aula seja mais acessível: 
1) Conhecer o estudante, descobrir o que ele conhece e quais os conhecimentos prévios que possa ter acerca do conteúdo. E verificar quais são os canais sensoriais mais utilizados;

2) Procurar na escola ou em instituição parceira o professor da Educação Especial, a fim de estabelecer contato e um possível trabalho colaborativo, onde cada professor irá contribuir com as especificidades de sua área;

3) Após, preparar a aula. Descrever as imagens e disponibilizar o texto para o aluno em braille, se for o caso, ou em formato acessível para leitores de tela, se o estudante for usuário desse tipo de recurso (docx e txt);

4) Criar materiais táteis. Por exemplo, demonstrar como são as representaçôes visuais das partículas ${ }^{6}$ apresentadas imageticamente no OED;

5) Explicar ao estudante como são as imagens do acelerador linear de Stanford. Uma maquete esboçando as principais estruturas do acelerador pode ser construída na sala de aula, ou anteriormente, a fim de que esse estudante consiga obter uma melhor compreensão;

6) O OED disponibilizado para este conteúdo é um vídeo, porém está inacessível para alunos cegos e baixa visão. Para enfrentar essa barreira, já que o vídeo é um importante recurso pedagógico a ser utilizado na educação, o recurso de Tecnologia Assistiva existente mais indicado é a áudio-descrição ${ }^{7}$, a mesma deve ser criada num momento anterior ao da aula e pode ser realizada na parceria entre professor da componente curricular Física e da Educação Especial.

Foram descritos e sugeridos 6 passos (roteiro) para o uso do OED de forma a torná-lo mais acessível aos estudantes com cegueira e baixa visão. Seguir os aspectos elencados pode contribuir significativamente para o processo educativo de todos os estudantes, em especial, daqueles que tenham cegueira e baixa visão. Como explicam Gonçalves et. al. (2013)

Há casos em que a natureza do curso parece ser um desafio a mais para os docentes na pro $\neg$ moção de um processo de ensino e aprendizagem para alunos deficientes visuais. Por exemplo, cursos de química, física e biologia exigem um conjunto de conhecimentos de caráter proce $\neg$ dimental que náo podem absolu $\neg$ tamente servir como critérios de exclusão de tais alunos. Cabe aos professores encontrar soluçóes para que os deficientes visuais também possam ser profissionais que trabalhem com ciência. O fato de haver químicos, físicos e biólogos com deficiência visual é um indicativo de certa efetivida $\neg$ de de processos formativos para estudantes com as características aqui destacadas. Se assim é, por que não ensinar ciências da natureza para deficientes visuais que frequentam a educação básica? (GONÇALVES et. al., 2013, p. 266).

A partir de açôes pedagógicas como as destacadas acima, percebemos a necessidade de propormos adaptaçôes aos recursos digitais que hoje adentram a sala de aula com a proposta de possibilitar um processo educacional mais significativo e moderno 
aos estudantes. Porém, destacamos que esse é um direito que deve ser assegurado a todos os alunos.

\section{Considerações finais}

Muitos foram os questionamentos que nortearam esse estudo e que possivelmente continuarão sem respostas. Talvez não sejam respostas prontas e acabadas que precisam os estudantes cegos e baixa visão matriculados no Ensino Médio nas diversas regiôes geográficas do país, mas sim de açôes governamentais mais efetivas no que tange seus processos educativos. Acreditamos que os mesmos aguardam por uma educação de qualidade e em isonomia de condiçôes, com materiais acessíveis e com professores com condiçóes de trabalho dignas que possam buscar e prover os melhores recursos pedagógicos a fim de enfrentar as barreiras educacionais.

A partir dos dados analisados podemos fazer algumas inferências, embora ainda incipientes, pois como já destacado, a análise não foi realizada com a consultoria de estudantes cegos e baixa visão e foi realizada no material disposto nos sites das editoras. Limites esses que devem ser superados em estudos posteriores. Dos quatro OED analisados, percebe-se que não há recursos de acessibilidade que possibilitem a participação de estudantes cegos e baixa visão.

Diante disso, pode-se concluir que programas do governo como o do livro didático (PNLD) parecem não acompanhar as discussões táo fomentadas em nosso país sobre a Educação Especial na perspectiva inclusiva, bem como as legislaçôes vigentes sobre o tema (BRASIL, 2008). Mesmo a exigência de acessibilidade estar presente no edital de inscrição para os editores e interessados em disponibilizar obras didáticas ao programa, não se percebe nenhuma ação diferente do livro no formato MecDayse.

Portanto, a parceria entre professores de diferentes áreas, como a da Educação Especial e da Física, pode se constituir como relevante no enfrentamento desta problemática: a inclusão de estudantes cegos e baixa visão em componentes curriculares de Ciências da Natureza. Acreditamos que cada professor contribui com informaçóes relevantes que podem ter implicaçóes no processo educativo destes estudantes.

Mesmo com todos estes indicativos de enfrentar coletivamente os problemas, a educação inclusiva só se tornará realidade no país se as condições de acessibilidade forem garantidas pelo governo, por meio de açôes efetivas e contínuas de fomento à inclusão, que possam até mesmo modificar e minimizar lacunas na formação inicial dos estudantes de cursos de licenciaturas nas universidades.

Muito já se avançou nas políticas públicas de inclusão e de acesso ao material didático gratuito no país, mas nesta breve análise realizada fica evidente que algumas "peças" ainda precisam ser ajustadas. Reconheçamos que esta foi a primeira oferta deste tipo de recurso para estudantes e que este foi um passo muito significativo na educação brasileira. 


\section{Referências}

AZEVEDO, A.C.; SANTOS, A.C.F. Ciclos de aprendizagem no ensino de física para deficientes visuais. Revista Brasileira de Ensino de Física, Sáo Paulo, v.36, n.4, 2014.

BRASIL. Ata da Reuniáo VII do Comitê de Ajudas Técnicas CAT, Secretaria Especial dos Direitos Humanos da Presidência da República, 2007.

BRASIL. Ministério da Educação. Secretaria de Educação Especial. Política Nacional de Educação Especial na Perspectiva da Educação Inclusiva, 2008.

BRASIL. Ministério da Educação. Fundo Nacional de Desenvolvimento da Educação. Edital de convocação para o processo de inscrição e avaliação de obras didáticas para o programa nacional do livro didático PNLD/2015, de 01 de 2013.

BRASIL. Ministério da Educação. Instituto Nacional de Estudos e Pesquisas Educacionais Anísio Teixeira. Censo Educaçáo Básica, 2014.

BRASIL. Ministério da Educação, Secretaria de Educação Básica. Guia de livros didáticos: PNLD 2015, física: ensino médio, 2014.

CABRAL, Leonardo Santos Amâncio; POSTALLI, Lidia Maria Marson; ORLANDO, Rosimeire Maria e GONÇALVES, Adriana Garcia. Formação de professores e ensino colaborativo: uma proposta de aproximação. Revista Ibero-americana de estudos em educaçáo, v. 9, n. 2, p. 390 - 401, 2014.

CAMARGO, Eder P. Saberes docentes para a inclusáo do aluno com deficiência visual em aulas de física. São Paulo: Editora Unesp, 2012.

CAMARGO, Eder P. Ensino de óptica para alunos cegos: possibilidades. Curitiba: Editora CRV, 2011.

CAMARGO, Eder P. É possível ensinar física para alunos cegos ou com pouca visão? Proposta de atividades de ensino de física que enfocam o conceito de aceleraçáo. Física na Escola, v.8, n.1, 2007.

CHAUÍ, Marilena. Janela da alma, espelho do mundo. In: NOVAES, Adauto et al. O Olhar. São Paulo, Companhia das letras, 1988.

GARCÍA, María L. B., CALDERA, María I. F. e JIMÉNEZ, Vicentte M. El aprendizaje de lấs ciencias em nińos ciegos y deficientes visuales. Revista Integración, Espańa, v.38, p. 25 - 34, 2002.

GIL PÉREZ, Daniel; MONTORO, Isabel F.; ALÍS, Jaime C.; CACHAPUZ, António e PRAIA, João. Para uma imagem não deformada do trabalho científico. Ciência \& Educaçáo, v. 7, n. 2, p. 125-153, 2001.

GONÇALVES, F. P.; REGIANI, Anelise M.; AURAS, Samuel R.; SILVEIRA, Thiele S.; COELHO, Juliana C. e HOBMEIR, Anna Karina T. A educação Inclusiva na formação de professores e no ensino de química: a deficiência visual em debate. Revista Química nova na Escola, v. 35, n. 4, p. 264-271, 2013.

GRACINDO, H. B. R. e FIREMAN, E. C. Laboratório de informática, os objetos digitais de aprendizagem e a visão do professor. Revista Educaçáo à Distância e Práticas Educativas Comunicacionais e Interculturais, n. 4 , p. $72-85,2010$

GRÉCIO, Lucimar Fernandes. A Acessibilidade dos Objetos Educacionais de Física: posibilidades para pessoas com deficiência visual. 2011. 167 f. Dissertaçáo (Mestrado em Educação) - Faculdade de Ciências e Tecnologia da , Universidade Estadual Paulista, Presidente Prudente, 2011.KOLITSKY, Michel A. 3D Printed Tactile Learning Objects: Proof of Concept. Journal of Blindness Innovation ande research, v. 4, n. 1, 2014.

KOLITSKY, Michel A. 3D Printed Tactile Learning Objects: Proof of Concept. Journal of Blindness Innovation ande research, v. 4, n. 1, 2014.

LAPLANE, Adriana L. F e BATISTA, Cecília G. Ver, não ver e aprender: a participação de crianças com baixa visão e cegueira na escola. Caderno Cedes, Campinas, v. 28, n. 75, p. 209-227, 2008.

MENDES, Enicéia G.; VILARONGA, Carla A. R. e ZERBATO, Ana P. O ensino colaborativo como apoio a inclusáo escolar: unindo esforços entre educação comum e especial. São Carlos: Edufscar, 2014. p. 160.

MELLO, A. G.; FERNANDES, F. B. M. Guia de Orientaçóes Básicas sobre Deficiência e Acessibilidade na 29a Reuniáo Brasileira de Antropologia. Cartilha sobre Deficiência e Acessibilidade 29a Reuniăo Brasileira de Antropologia, Universidade Federal do Rio Grande do Norte (UFRN), Natal, 2014.

NUNES, Elton V.; BUSARELLO, Raul I.; DANDOLINI, Gertrudes; SOUZA, João A. de; ULBRICHT, Vania R. e VANZIN, Tarcísio. Construçáo de objetos de aprendizagem acessível: foco na aprendizagem significativa. Cadernos de Informática, v. 6, n. 1, p. $245-248,2011$. 
NOVAES, A. De olhos vendados. In: NOVAES, Adauto et al. O Olhar. São Paulo, Companhia das Letras, 1988.

SÁ, Elizabet D.; CAMPOS, Izilda M. e SILVA, Myriam B. C. Formaçáo continuada a distância de professores para o atendimento educacional especializado - Deficiência visual. Brasília, 2007.

SEEMAN, Paulo Augusto Almeida; LIMA, Rosângela A. Ferreira e LIMA, Francisco José. Áudio-descrição no acordo ortográfico da Língua Portuguesa: um estudo morfológico. Revista Brasileira de Traduçáo Visual, v. 13 , n. 13,2012

SOLER, Miquel- Albert. Didáctica multissensorial de las ciencias: un nuevo método para alumnos ciegos, deficientes visuales, y también sin problemas de visión. Barcelona: Ediciones Paidós Ibérica, 1999.

TORRES, Elizabeth F.; MAZZONI, Alberto A. e MELLO, Anahi Guedes de. Nem toda pessoa cega lê em Braille nem toda pessoa surda se comunica em língua de sinais. Educaçáo e Pesquisa, v.33, n.2, p. 369 - 385 , 2007.

TORRES, Elizabeth e MAZZONI, Alberto A. Conteúdos digitais multimídia: o foco na usabilidade e acessibilidade. Revista Ciência da Informaçáo, v. 33, n. 2, p. 152 - 160, 2004.

VIVARTA, Veet. Mídia e Deficiência. São Paulo: Andi - Fundação Banco do Brasil, 2003.

VYGOTSKI, L.S. Obras Escogidas V Fundamentos de Defectologia. Editora Pedagógica, Moscú. De La presente edición, 1983.

VOOS, Ivani C.; RÔDRIGUES, Jeremias S.; MACAN, Aline G.; JORDÃO, Vírginia e SOUZA, Bruno J. O ensino colaborativo em aulas de Matemática com estudantes surdos e com deficiência. In: CONGRESSO BRASILEIRO DE EDUCAÇÃO ESPECIAL, 7., São Carlos, 2016. Anais... São Carlos: CBEE, 2016. p. 1 - 12.

\section{Notas}

${ }^{1}$ Vivarta (2003), explica que a barreira pedagógica e metodológica consiste nas barreiras impostas pelo fato de os instrumentos e artefatos culturais suporem um usuário ideal e abstrato, desprovido de quaisquer deficiências sensoriais, intelectuais ou de mobilidade. Sua superação passa pela adoçáo da noção de desenho universal e pela utilização de tecnologias assistivas (MELLO E FERNANDES, 2014, p. 11).

${ }^{2}$ Mello e Fernandes embasados em Vivarta (2003), explicam que a barreira comunicacional e informacional "consistem nas rupturas comunicacionais comuns, por exemplo, nas trocas sociais entre surdos e ouvintes, nas dificuldades de comunicação de pessoas com paralisia cerebral e com autismo, dentre outros. A eliminação de barreiras comunicacionais e informacionais exige diferentes recursos de acessibilidade, desde a presença de intérpretes de Libras para as pessoas surdas usuárias de Libras e da tecnologia da estenotipia no caso de serem surdas oralizadas e até a utilização de outras tecnologias assistivas, por exemplo, as tecnologias de comunicação alternativa, além da conversão de materiais impressos em tinta para formatos acessíveis a pessoas com deficiência visual, como é o caso da impressão Braille e a produçăo de textos digitalizados" (MELLO E FERNANDES, 2014, p. 10 - 11).

${ }^{3}$ Embora o edital de convocação descreva no item "4.2.17. Os livros digitais adquiridos deveráo ser disponibilizados de forma gratuita aos alunos e professores em domínio virtual da própria editora e permanecerem disponíveis até, no mínimo, 28.02.2018” (BRASIL, 2013, p. 4).

${ }^{4} \mathrm{O}$ Ministério da Educação lança o Mecdaisy, uma solução tecnológica que permitirá a produção de livros em formato digital acessível, no padrão Daisy. Desenvolvido por meio de parceria com o Núcleo de Computaçáo Eletrônica da Universidade Federal do Rio de Janeiro - NCE/UFRJ - o Mecdaisy possibilita a geração de livros digitais falados e sua reprodução em áudio, gravado ou sintetizado. Este padrão apresenta facilidade de navegaçáo pelo texto, permitindo a reprodução sincronizada de trechos selecionados, o recuo e o avanço de parágrafos e a busca de seçóes ou capítulos. Possibilita também, anexar anotaçôes aos arquivos do livro, exportar o texto para impressāo em Braille, bem como a leitura em caractere ampliado. Todo texto é indexado, facilitando, assim, a manipulação através de índices ou buscas rápidas (http://intervox.nce.ufrj.br/mecdaisy/).

${ }^{5} \mathrm{O}$ livro digital, bem como o OED das coleçóes analisadas estão disponíveis em: http://pnld2015interno.scipioneatica. com.br/pnld2013/default.aspx?opc $=96 \&$ art $=482 \&$ set $=0 \&$ url $=$ compreendendo-a-fisica. e, respectivamente. Opção OED no menu esquerdo, e em seguida opção LHC - O grande colisor de hádrons, página 305 na primeira coleção e página 245 na segunda. Acesso em 09 de fevereiro de 2015.

${ }^{6}$ Usualmente as partículas subatômicas são representadas por esferas muito pequenas. Isso é uma representação falha, mas é a que de certa forma facilita o entendimento de alguns fenômenos, como as "colisōes". Não há uma representação plenamente satisfatória de "colisóes" entre partículas subatômicas como existe em colisóes na mecânica clássica, onde dois objetos se chocam, pois nesse caso tratamos de dois entes físicos com comportamentos duais (onda-partícula) 
muito complexos que estão interagindo e simplificamos como se fossem duas partículas bem definidas no espaço. Essa adaptação é muito complicada de pensar, e os erros de interpretaçáo podem se tornar ainda maiores tanto para o aluno vidente como para o aluno deficiente visual.

${ }^{7}$ A áudio-descrição, inicialmente pensada para descrever imagens para pessoa com deficiência visual, mostrou-se um recurso semiótico de grande potencial também para uso de pessoas com deficiência intelectual, e hoje é reconhecidamente um recurso de tecnologia assistiva, na área da comunicação (Decreto Federal 5296/2004) (SEEMAN, LIMA e LIMA, 2012, p.4)

\section{Correspondência}

Gabriela Kaiana Ferreira - Universidade Federal do Paraná, Centro de Estudos do Mar. Avenida Beira Mar, s/n. Pontal do Sul. CEP: 85950-000. Pontal do Paraná, Paraná, Brasil.

E-mail: nicavoos@yahoo.com.br - gabikaiana@gmail.com

Recebido em 12 de outubro de 2016

Aprovado em 24 de maio de 2017 